\title{
Fronteras y jerarquías familiares en casos de colocaciones domésticas en la ciudad y la provincia de Buenos Aires, 1940-1960*
}

\section{Borders and family hierarchies in cases of domestic colocaciones in the city and province of Buenos Aires, 1940-1960}

\author{
Inés Pérez ${ }^{* *}$ \\ (iD https://orcid.org/0000-0002-5266-9350 \\ Consejo Nacional de Investigaciones Científicas y Técnicas \\ Universidad Nacional de Mar del Plata, Argentina \\ inesp18@yahoo.com
}

Resumen: Este artículo analiza las fronteras de lo familiar a la luz de tres casos de colocaciones domésticas en la Argentina de las décadas centrales del siglo xx. Se utiliza un corpus de fuentes diversas, que incluye entrevistas y lega-

* La investigación de la que resultó este texto fue financiada por la Secretaría de Investigación de la Universidad Nacional de Mar del Plata. Título del proyecto: Género y Trabajo en el Medio Familiar: Afecto, Economía y Desigualdades (15/-HUM567/18). Agradezco las sugerencias de los evaluadores anónimos. Quiero agradecer, además, la atenta lectura y comentarios de María Bjerg, Andrea Torricella, Débora Garazi y Guadalupe Blanco Rodríguez.

** Doctora en Ciencias Sociales y Humanas. Líneas de investigación: historia del trabajo doméstico, estudios de género, historia de la familia y la vida cotidiana.

cómo citar: Pérez, I. (2020). Fronteras y jerarquías familiares en casos de colocaciones domésticas en la ciudad y la provincia de Buenos Aires, 1940-1960. Secuencia (106), e1589. DoI: https://doi.org/10.18234/ secuencia.v0i106.1589 
jos de menores de instituciones públicas, para mostrar distintas formas que podían adquirir las relaciones originadas en este tipo de colocaciones. Puntualmente, se explora el lugar que en ellas tenían el afecto y las fronteras emocionales, y los modos en que circulaba el dinero. El artículo busca mostrar la diversidad de relaciones en las que se intercambiaba trabajo doméstico y de cuidados por dinero en este periodo, para señalar el lugar de la afectividad en la construcción de las desigualdades y jerarquías sociales.

Palabras clave: trabajo doméstico y de cuidados; colocaciones domésticas; afecto; fronteras familiares; servicio doméstico.

Abstract: This article analyses family boundaries in the light of three cases of colocaciones domésticas in the middle decades of the 20th century Argentina. Using a corpus of diverse sources, which includes interviews and children's files opened by public institutions, it shows different forms that the relations originated in colocaciones could acquire. Specifically, it explores the place affect and emotional boundaries had in them, and the ways in which money circulated. The article aims to show the diverse relations in which domestic and care work were exchanged for money in this period, to highlight the relevance of affection in the construction of social inequalities and hierarchies.

Keywords: domestic and care work; colocaciones domésticas; affection; family borders; domestic service.

Recibido: 15 de febrero de 2018 Aceptado: 16 de noviembre de 2018 Publicado: 24 de octubre de 2019

\section{INTRODUCCIÓN}

$\mathrm{E}_{\text {nores era una práctica relativamente habitual, que podía estar o no me- }}$ diada institucionalmente, y suponía la entrega de niños y niñas a familias para las que realizaban distintos trabajos, las más de las veces domésticos, a cambio de manutención, habitación y educación. Si para los agentes estata- 
les, la colocación laboral suponía la posibilidad de brindar la formación en un oficio a niños y niñas que se consideraban en peligro, para las familias de escasos recursos económicos podía ser una estrategia temporal en tiempos de apremio económico (Aversa, 2014; Leo, 2015). Su extensión en ese periodo ha llevado a algunas investigadoras a poner en cuestión el grado de mercantilización del servicio doméstico ${ }^{1}$ (Allemandi, 2017; Aversa, 2014).

Ya desde fines del siglo XIX, la colocación de menores recibió distintas críticas, centradas en la posibilidad de los guardadores de eludir sus responsabilidades, tanto económicas como en relación con la educación de las niñas y los niños. Esas críticas redundaron en cambios normativos como la prohibición legal del trabajo de menores de catorce años en el servicio doméstico en 1924 (Allemandi, 2017). Más tarde, la sanción del Decreto Ley 326 en 1956 marcaría un hito significativo en el avance de la laboralización/mercantilización del servicio doméstico que venía teniendo lugar desde hacía décadas (Remedi, 2012). La sanción de la primera ley de adopción en 1948 también había cambiado las condiciones en las que un niño, niña o joven podía ocupar dentro de una familia que no era la suya de origen (Villalta, 2012), en un escenario en que las nociones más centradas en el afecto y la proximidad emocional en la crianza ganaban fuerza (Cosse, 2010; Rustoyburu, 2012).

Sin embargo, incluso después de 1960, muchas niñas y adolescentes seguirían siendo colocadas para el servicio por sus familiares e incluso por tribunales de menores y otras agencias estatales. ${ }^{2}$ El hecho de que el Consejo de Protección del Menor, dependiente del Estado nacional (en adelante el Consejo o el Consejo del Menor), contara todavía en los años sesenta con una bolsa de trabajo destinada mayormente a este tipo de colocaciones es un dato significativo. Es más, esta práctica siguió siendo activa en la producción de sentidos en torno de la vida familiar, el trabajo doméstico y de cuidados, y quienes lo realizaban (Pérez, 2018).

¿Qué indica la persistencia de las colocaciones de menores hacia mediados del siglo xx en relación con los límites de la mercantilización/laboralización del servicio doméstico?, ¿de qué modo tensiona la categoría de empleo

1 A lo largo del artículo se habla de "servicio doméstico" puesto que se trata de una categoría nativa: es la que se utilizaba en la Argentina durante el periodo analizado.

${ }^{2}$ Gentili (2018) ha encontrado situaciones similares también para este periodo en la provincia de Córdoba. 
doméstico? ${ }^{3}$ En la Argentina de mediados del siglo xx, la fórmula habitual en los contratos mediados primero por la Sociedad de Beneficencia de la Capital ${ }^{4}$ y luego por distintos institutos estatales incluía la obligación de dar el trato de "hija", pero el sentido de esta frase no es explicitado. El trato "familiar" al que aluden los contratos permite dar cuenta de la heterogeneidad y complejidad de las relaciones en las que el trabajo doméstico y de cuidados era intercambiado. ¿Cómo informaron esas imágenes los imaginarios en torno de lo que era justo y legítimo en este tipo de vínculos en la Argentina de las décadas centrales del siglo xx?, ¿qué jerarquías imprimía el "trato familiar"?

En este artículo abordo tres casos que muestran distintas formas que podían adquirir las relaciones entre niñas colocadas y sus guardadores en la ciudad y la provincia de Buenos Aires entre 1940 y 1960. En el primero, los crecientes niveles de mercantilización de dicho vínculo culminaron con una trayectoria vital en el empleo doméstico; el segundo es el de una joven colocada con diferentes guardadores/empleadores, ${ }^{5}$ de cuyos hogares fue sistemáticamente expulsada; en el tercero, la niña pasó a formar parte de la familia de sus guardadores, aunque no legalmente y sin que ello supusiera un trato igualitario.

Los tres casos analizados presentan elementos comunes. Los tres se iniciaron a fines de la década de 1940 y se desarrollaron en el litoral pampeano, la región del país más fuertemente industrializada e influenciada por las olas migratorias, tanto ultramarinas como internas. Dos de las niñas fueron colocadas por sus propias madres, sin intervención institucional, con familias que residían en la ciudad de Dolores, una localidad del sureste de la provincia de Buenos Aires, a $200 \mathrm{~km}$ de la Capital Federal, que desde mediados del siglo xIX concentró distintas funciones gubernamentales y fue un centro relevante de la región. Las sucesivas colocaciones de la tercera, en cambio,

3 Tomo esta categoría del trabajo de Lerussi (2014), que enfatiza los aspectos mercantilizados del trabajo doméstico y los cuidados remunerados.

${ }^{4}$ La Sociedad de Beneficencia de Buenos Aires fue creada en 1823 por el entonces presidente de Argentina, Bernardino Rivadavia, y su gestión fue encargada a un grupo de damas de la elite porteña. Tuvo un importante papel en la administración de distintas instituciones de caridad y beneficencia. Entre las muchas instituciones bajo su órbita, se encontraban hospitales, hospicios y asilos. Su accionar a lo largo de más de un siglo tuvo una incidencia insoslayable en la vida de los sectores populares. Hasta 1880 dependió del gobierno de la provincia de Buenos Aires. En ese momento cambió su nombre a Sociedad de Beneficencia de la Capital. En 1946, fue intervenida por el gobierno peronista, y fue disuelta en 1948.

${ }^{5}$ Se utilizan las categorías de guardadores y empleadores porque ambas aparecen en el legajo analizado. 
fueron mediadas por diferentes instituciones y tuvieron lugar en la ciudad de Buenos Aires.

Las trayectorias vitales analizadas en este artículo fueron reconstruidas a partir de distintos tipos de fuentes. En el primer caso, entrevisté a quien fue colocada para el servicio cuando tenía once años, en 1958. La entrevista fue realizada en su casa, en la localidad de Dolores, en 2016. El segundo está reconstruido a partir de distintos documentos que se conservan en un legajo iniciado por la Sociedad de Beneficencia de la Capital en 1948 y que culmina en $1970 .{ }^{6}$ Para el tercero realicé distintas entrevistas a personas cercanas a la niña colocada: una de sus amigas más íntimas, una de sus sobrinas, la nieta y el bisnieto de quienes fueran sus guardadores. Las entrevistas también fueron realizadas en 2016, en Dolores, donde residen los informantes. ${ }^{7}$

Aunque se trata de sólo tres casos, su relevancia se justifica por el tipo de abordaje propuesto, que difícilmente podría realizarse trascendiendo la escala individual. Es en los detalles de cada una de las historias donde aparecen los elementos más interesantes para el análisis de los problemas trabajados aquí. Las fuentes históricas utilizadas tienen una densidad que quedaría desdibujada en otro tipo de lectura. Se trata, además, de fuentes escasamente transitadas por la historiografía de las colocaciones domésticas. En el caso de las fuentes orales, no ha sido una fuente disponible puesto que la mayor parte de las investigaciones se han centrado en periodos previos. Existen, además, dificultades para localizar a las y los informantes. Los legajos de menores de la Sociedad de Beneficencia de la Capital, por su parte, han sido abiertos a la consulta pública recientemente. Se trata incluso de un material que aún no está enteramente catalogado. El legajo aquí trabajado fue seleccionado de entre más de 100 relevados, y se distingue por la longitud del periodo que cubre, que llega hasta 1970, y por la riqueza del material que contiene.

${ }^{6}$ Leg. 59.991. Fondo Secretaría de Niñez, Infancia y Familia. Archivo Intermedio. Archivo General de la Nación (en adelante AGN), Argentina. Cada vez que un niño o niña era internado en alguna de las instituciones dependientes de la Sociedad de Beneficencia de la Capital se abría un legajo. Se iniciaba con una solicitud de internación, a la que luego se agregaban distintos documentos (informes médicos, ambientales, certificados de nacimiento, matrimonio, etc.). Allí se reunía toda la información producida en torno de ese niño o niña hasta que salía del sistema, ya fuera porque volvía con sus padres o familiares, porque cumplía la mayoría de edad, o porque fallecía.

7 Sobre las posibilidades y las limitaciones de las fuentes orales y las historias de vida, véase Arfuch (2002); Portelli (2007); Thompson (1988). 
¿Qué es lo que hace que un vínculo sea caracterizado como familiar y qué implica esa caracterización? La idea de familia ha variado histórica y geográficamente, además de tener diferentes connotaciones para distintos grupos sociales (Segalen, 2013). En una lectura ya clásica, Schneider (1980) señalaba que el amor y la solidaridad duradera difusa desempeñaban un papel central en la distinción de las relaciones familiares de aquellas que no lo eran. ${ }^{8} \mathrm{De}$ acuerdo con este antropólogo, la distinción entre amor y dinero era clave para determinar el tipo de vínculos que podían caracterizarse como familiares.

Ahora bien, en esta conceptualización, las desigualdades y jerarquías que estructuran el mundo familiar quedan desdibujadas. Ser de la familia no significa tener un trato igualitario; la familia es un ámbito marcado por las jerarquías y regido por el estatus, dados por marcas de género y edad; es también un espacio de coerción, violencia y desigualdad (Fraser, 1997). Siguiendo a Bourdieu (1994), la familia puede pensarse como cuerpo que funciona de manera unificada en ciertas circunstancias, y como campo en el que existe un reparto desigual de poder y capital. Si el espíritu de familia supone la existencia de la expectativa de protección, o de una solidaridad duradera difusa en términos de Schneider, ella está atravesada por marcadas jerarquías.

Además, como ha advertido Zelizer (2009), no es sólo que los vínculos familiares sean el marco para el intercambio de bienes, trabajo y dinero, sino que la propia legitimidad de ese intercambio deriva de la posibilidad de caracterizarlos así. En particular, en las relaciones en las que se intercambia trabajo doméstico y cuidados por dinero, el afecto tiene un peso considerable. En ese marco, lo que Goldstein (2003) identificara como ambigüedad afectiva cimienta un vínculo complejo que habilita prácticas no habituales en otras relaciones laborales. De hecho, es usual escuchar que los empleadores describan su relación con quien se emplea en el servicio doméstico en sus hogares

${ }^{8}$ Schneider (1980) sitúa su análisis en los Estados Unidos de los años sesenta y setenta. Aquí utilizaremos el esquema teórico que propone para pensar la Argentina en ese mismo periodo. En términos normativos, para este autor el parentesco se sostiene o bien en un vínculo sanguíneo o en un código de conducta compartido (el matrimonio). Sin embargo, cuando analiza la persona como pariente, señala la relevancia de las decisiones de los sujetos en torno de quiénes, dentro de ese universo de posibles parientes, en realidad son considerados como tales. La clave está en la cercanía, física, genealógica y emocional, a partir de las que se sostienen o no relaciones de solidaridad duradera difusa. En este texto voy a tensar la lectura de Schneider para incluir otras posibles relaciones en las que existe dicha solidaridad, pero no un vínculo sanguíneo o por matrimonio. El propio Schneider incluye un ejemplo de este tipo: se trata de una informante que consideraba como pariente a una amiga con la que compartía su casa. 
"como de la familia", lo que da cuenta del lugar liminal de estas relaciones. El hecho de que quienes en su enorme mayoría realizan ese trabajo sean mujeres de sectores subalternos en términos de clase y muchas veces también racializados, es clave para explicar el lugar subordinado que se les asigna en las jerarquías familiares. El afecto y la condición "cuasifamiliar" estructuran las desigualdades que caracterizan estas relaciones.

Si el empleo doméstico está situado en un espacio fronterizo entre lo laboral y lo familiar, el caso de las colocaciones domésticas es aún más intrincado. ¿Cuál era el vínculo de las niñas colocadas con los guardadores y en qué casos era caracterizado como familiar?, ¿de qué manera circulaba el dinero en esas relaciones?, ¿qué relevancia tenían el afecto y las fronteras emocionales ${ }^{9}$ en la demarcación de quienes formaban o no parte de una familia? ¿Qué tipo de desigualdades y jerarquías habilitaba el afecto y la descripción de un vínculo como "familiar"? Los límites en la mercantilización del servicio doméstico explican buena parte de los obstáculos que las trabajadoras domésticas han tenido que afrontar para el reconocimiento y la observación de sus derechos laborales. Abordar estas preguntas puede ayudar a comprender más cabalmente las relaciones y los imaginarios que obturaron la laboralización de este sector.

\section{OFELIA}

Ofelia nació en 1947 en San Clemente del Tuyú, una localidad costera de la provincia de Buenos Aires cuya actividad dominante era (y sigue siendo hasta el presente) el turismo estival. San Clemente era un pueblo muy pequeño, al que sólo llegaban los camiones con mercadería en verano por caminos difíciles, cubiertos muchas veces por arena. El mate cocido que ella y sus herma-

${ }_{9}$ En este punto, el concepto de fronteras emocionales ha sido desarrollado recientemente por Vallagårda, Alexander y Olsen (2017) para dar cuenta del límite entre formaciones emocionales distintas, es decir, entre grupos de estructuras emocionales ordenadas en un patrón particular. Las formaciones emocionales, sostienen estas autoras, dan cuenta de la existencia de un cierto nivel de coherencia en las concepciones sociales del comportamiento emocional apropiado o incluso comprensible en diferentes situaciones. Aunque las autoras usan el concepto para referir a límites entre formaciones emocionales que tienen dominancia a nivel societal, quizá también permita precisar fronteras emocionales de clase. El caso de las niñas colocadas resulta de particular interés para explorar dichas fronteras puesto que las relaciones que las vinculan con sus guardadores implican un encuentro entre personas formadas de acuerdo con parámetros emocionales de clase distintos, en un espacio que, al menos en términos modélicos, está regido por el afecto. 
nos tomaban como desayuno en invierno, amargo porque no había dónde comprar azúcar, condensa en los recuerdos de Ofelia la imagen, más que de la pobreza de su familia, de la escasez de un pueblo donde "no había nada". Ella era la tercera de siete hermanos, tres varones y cuatro mujeres, a los que luego se sumarían cuatro hermanos más, hijos de su madre y su segunda pareja. Desde muy pequeña, Ofelia colaboraba con los ingresos familiares: su madre y su abuela lavaban ropa para los turistas y era ella la que iba y venía con los encargos de los clientes; pero a pesar de los esfuerzos familiares, en invierno había poco trabajo.

En 1958, cuando su padre falleció, su madre colocó a sus hijos con distintas familias de Dolores. Ofelia fue colocada con la familia Ortega para realizar trabajo doméstico. En ese entonces, Ofelia tenía once años. Allí estuvo hasta los 18 años, cuando su hermana mayor la reclamó para que la ayudara con su pequeña hija. En esa casa, Ofelia recuerda que "estaba hecha una reina. Era la mucama, pero buenísima la señora. Un pan de dios. [...] Así que sí, ahí la pasé de diez. Ahí me cambió la vida. ${ }^{10}$ La forma en que Ofelia habla de su situación en lo de los Ortega es significativa: trabajaba como "mucama", siendo una niña y lejos de su familia de origen, pero enfatiza lo bien que estuvo allí. Posiblemente el contraste con lo que había vivido y la gratitud que se esperaba de ella, la deferencia que se le exigió - que aún se le exige a quienes se desempeñan en el sector doméstico (Gorbán y Tizziani 2014; Rollins, 1985)-, expliquen que lo presente en esos términos.

Para ese momento ya regía el Decreto Ley 326, que prohibía el trabajo de menores de catorce años en el servicio doméstico. La situación inicial de Ofelia en esa casa transgredía lo regulado legalmente tanto en relación con su edad como a las condiciones en las que estaba. Podríamos caracterizarla como la de un empleo doméstico sin retiro, pero inicialmente no cobraba un salario por su trabajo. Los términos con los que estaba en casa de los Ortega se asemejaban más a los de un arreglo de crianza que a los de un empleo. Trabajaba a cambio de alimento, vestido y alojamiento. Allí, además, aprendió el oficio que desarrollaría el resto de su vida. Ofelia trabajó para muchas otras familias, pero los Ortega tienen un sitio especial en su memoria: "Ahí me terminaron de criar, me dieron de comer, me dieron lo mejor, mi ropa, mis

${ }^{10}$ A lo largo de este apartado, las comillas serán utilizadas para citar fragmentos de la entrevista realizada a Ofelia, el 30 de noviembre de 2016, en Dolores, Provincia de Buenos Aires, Argentina. 
salidas, la educación, aprendí muchas cosas [...] Aprendí a trabajar, aprendí lo que eran las cosas, aprendí lo que era el Puloil..."11

Como en el caso de los sirvientes de curso de vida (Anderson, 1988; Hareven, 1995), la relación de crianza fue una de aprendizaje, de transición hacia la vida adulta, pero también hacia la vida urbana y a sus consumos. Como en la colocación de menores de principios de siglo en diversos países latinoamericanos, la del servicio doméstico sería menos una etapa que una posición que Ofelia mantendría hasta la vejez (Milanich, 2009), aunque su estatus y las condiciones en las que desarrolló esa labor cambiaron incluso dentro de la casa de los Ortega. Si inicialmente lo que Ofelia recibía a cambio de su trabajo era techo, comida y vestido, alrededor de los quince años comenzó a cobrar un monto mensual de dinero. Quienes propusieron el nuevo arreglo fueron los dueños de casa, entre quienes había desacuerdos en torno del grado en que sería considerada como una trabajadora: "el señor siempre le decía a la señora que tenían que hacerme los descuentos [aportes previsionales] para el día de mañana. Y la señora le decía 'no, no le vamos a hacer nada porque vas a ver que ella se va a casar pronto, se va a casar joven, no, no, no'. Así que nunca me hicieron descuentos ellos ahí."

Resulta significativo que los elementos que limitaban su caracterización como trabajadora fueran los mismos que en la doctrina jurídica de la época se usaran para restringir los derechos laborales de las empleadas domésticas. Representadas como mujeres solteras, sin cargas familiares, que serían alcanzadas por la seguridad social en tanto esposas de un trabajador, se sostenía que era innecesario incluirlas en el sistema previsional (Deveali, 1956, pp. 434-439). En la voz de los Ortega, evitar hacer los aportes previsionales era presentado como una apuesta por un futuro mejor para Ofelia: el de un casamiento joven. Independientemente de que no coincidiera con las trayectorias vitales de la mayoría de quienes se desempeñaban en esta ocupación, la imagen del servicio doméstico como una etapa de transición hacia la vida adulta y el matrimonio era común a otros discursos de la época (Vázquez Lorda, 2010).

En cualquier caso, el pago en dinero supuso un cambio en el estatus de Ofelia. En principio, fue un reconocimiento de su carácter de trabajadora. Si inicialmente era tratada como una aprendiz, a la que había que enseñarle el trabajo y a la que había que ayudar en su ejecución, el pago de un

${ }^{11}$ El Puloil es la marca de un polvo abrasivo de uso muy difundido en la Argentina de mediados del siglo $\mathrm{xx}$. 
salario la ubicaba en la posición de quien ya lo realizaba y merecía una paga por ello. Ahora bien, Ofelia ya hacía las tareas sola a los doce o trece años, pero recién comenzó a cobrar un salario a los quince años. El pago en dinero supuso también su reconocimiento como persona responsable, si no adulta completamente (en términos legales, pero también sociales, sólo alcanzaría ese estatus después de contraer matrimonio, cuando tuviera 18 años), sí lo suficiente como para manejar dinero. La prueba de esa responsabilidad estaba en el ahorro que le permitía enviar una suma periódica a su madre.

En las colocaciones de menores mediadas por el Estado contemporáneas a la de Ofelia, se obligaba a los guardadores a depositar una parte del dinero que correspondía a la retribución mensual por las tareas realizadas en una cuenta que sólo le sería entregada a la menor al cumplir la mayoría de edad, para garantizar ese ahorro. ${ }^{12}$ Esta situación podía implicar la ausencia del pago de los servicios e incluso perdurar aun cuando las trabajadoras ya fueran mayores de edad. Algunos empleadores insistían en que no les pagaban los sueldos, guardándolos ellos en una cuenta bancaria específica, para protegerlas de sí mismas y de los peligros de la vida urbana. ${ }^{13}$ En el caso de Ofelia, el pago de un salario implicaba un cambio de estatus: ya no era, al menos no enteramente, una niña dependiente en términos económicos. ${ }^{14}$

Para cuando empezaron a pagarle un salario, Ofelia había probado sus cualidades en relación con el uso del dinero. Como en el caso de los niños mexicanos de principios de siglo analizado por Blum (2011), Ofelia demostraba ser una buena hija al enviarle parte del dinero que ganaba regularmente a su madre. En el relato de su vida, se presenta como una pobre decorosa, que sabía guardar su lugar y no se "aprovechaba" de las ayudas que recibía. Recuerda, por ejemplo, cómo, de niña, cuando con sus hermanos llevaban los paquetes de ropa, en ocasiones los clientes de su madre y su abuela los invitaban a sentarse a la mesa y ellos, por vergüenza, respondían que ya habían comido, incluso cuando tuvieran hambre. Del mismo modo, Ofelia nunca se sentó a la mesa con los Ortega: "comíamos en la cocina, con la cocinera.

${ }^{12}$ Esto puede observarse en los contratos de colocación de menores de este periodo, tanto los establecidos en el marco de las agencias de minoridad dependientes del Estado nacional, como en los mediados por los tribunales de menores de la provincia de Buenos Aires.

13 Véase, por ejemplo, Acta 337/1965. Fondo Tribunal del Trabajo Doméstico. AGN, Argentina.

14 Zelizer (1994) ha señalado la dependencia económica como uno de los elementos que caracterizan la definición moderna de la infancia. 
Siempre en la cocina, con la cocinera. Pero a la noche cuando el señor ya se iba a acostar, íbamos al comedor con la señora, nos hacía ir al comedor a mirar televisión. Yo jugaba a las cartas, a la canasta, con la señora, y la cocinera tejía.”

Como se observa en el fragmento anterior, saber guardar su lugar no impedía que Ofelia compartiera escenas familiares con los Ortega. Como he mostrado en otras investigaciones, entre mediados de la década de 1950 y fines de la de 1960, el mismo tipo de escenas eran también recuperadas en los juicios laborales iniciados en casos de servicio doméstico por empleadores que insistían en presentar la relación con quien los demandaba no como una de trabajo, sino como una de familia (Pérez, 2013, 2018; Pérez y Canevaro, 2015). Así, por ejemplo, en 1966, una mujer sostenía que quien había entablado una demanda en su contra había ocupado en su casa el lugar de "ayudante", ${ }^{15}$ no de empleada doméstica, y para probarlo señalaba que tuteaba a sus hijas, salía con ellas, veía por televisión los programas que deseaba, y que "un poco por compasión, por su situación y por su modo agradable y servicial, fue en [su] casa una hija más" ${ }^{16}$

¿De habérselos preguntado, o de haber sido demandados ante la justicia, los Ortega habrían calificado a Ofelia como "una hija más"?, ¿qué marcaba en todo caso ese estatus? Ofelia no los presenta como padres sustitutos, ni a ellos ni a sus sucesivos empleadores, aunque con todos tuvo vínculos marcados por el afecto. Cuando Ofelia se fue de su casa, los Ortega fueron a buscarla muchas veces para que volviera. Ella siguió yendo a ver a los Ortega, pero no a trabajar, sino a pasar tiempo con ellos. Durante algunos años, solía ir a pasar las tardes con ellos, llevando consigo a la hija de sus nuevos empleadores. No sólo tuvo afecto por ellos, sino que, en los términos de Schneider (1980), mantuvo lazos de una solidaridad duradera difusa. Algunos de sus empleadores la ayudaron en situaciones difíciles que tuvo que atravesar, como el apresamiento de uno de sus hijos.

¿El parentesco admitía gradaciones? En ese caso, quizá podríamos pensar que Ofelia recibió un tratamiento que no la ubicaba plenamente en las familias de sus empleadores, pero sí en una suerte de periferia, en la que se esperaba deferencia y gratitud a cambio de ser integrada en una compleja red de protección que podía activarse cuando fuera necesario. A diferen-

${ }^{15}$ Este es el término utilizado en el juicio.

${ }^{16}$ Acta 331/1966, fs. 5 y 6. Fondo Tribunal del Trabajo Doméstico. AgN, Argentina. Se evita copiar la carátula del juicio para preservar la identidad de las personas involucradas. 
cia de los casos que veremos a continuación, el núcleo de la vida familiar de Ofelia seguiría siendo su familia de origen y, luego, la establecida a partir de su matrimonio. Fueron esas relaciones las que activaron los vínculos con los guardadores y, luego, empleadores: fue colocada en casa de los Ortega para ayudar a su madre; se fue de allí cuando su hermana se lo pidió; recurrió a sus antiguos empleadores cuando su hijo fue preso. Podríamos decir que Ofelia, en este sentido, formaba parte de más de una red de parentesco, aunque con posiciones de diversa centralidad y jerarquía. Entre dichas redes había una frontera, pero era una frontera abierta, que Ofelia podía transitar, aunque ese tránsito tuviera límites preciosos en las jerarquías familiares.

El caso de Ofelia permite plantear algunas preguntas en torno a los sentidos del afecto. En un análisis de cartas de migrantes portugueses enviadas entre 1870 y 1920, Borges (2016) señalaba que obediencia y deber son parte del lenguaje del amor y la familia. El dinero enviado regularmente, la respuesta a la solicitud de ayuda, son las narrativas que el amor asumía en esas cartas. Es también la que asumía en la descripción de Ofelia de su relación con su familia de origen, donde la familia era identificada con el deber y el afecto, como obediencia y observación de ese deber. El afecto como obediencia era también clave en la relación con sus guardadores y empleadores. A cambio de obediencia, deferencia y gratitud, Ofelia podía esperar protección, podía franquear las fronteras familiares. La solidaridad duradera difusa estaba marcada por fuertes jerarquías entre los que protegen y las que obedecen.

\section{MICAELA}

Micaela nació en el partido de Vicente López, en el Gran Buenos Aires, en octubre de $1948 .{ }^{17}$ Cuando tenía seis meses fue internada en la Casa Cuna ${ }^{18}$

${ }^{17}$ La historia de Micaela está reconstruida a partir de los datos que constan en el legajo que sobre ella abriera la Sociedad de Beneficencia de la Capital. Todas las citas textuales de esta sección fueron tomadas del Legajo 59.991. Fondo Secretaría de Niñez, Infancia y Familia. Archivo Intermedio. AGN, Argentina. El legajo sigue la trayectoria de la niña, y luego de la joven, hasta febrero de 1970, tras haber alcanzado la mayoría de edad, a los 21 años.

${ }^{18}$ La Casa Cuna es un hospital pediátrico fundado en 1779 como "Hospital y Casa de Niños Expósitos". Recibió ese nombre porque albergaba niños "expuestos" o abandonados. En 1823 pasó a depender de la Sociedad de Beneficencia de Buenos Aires, hasta 1948, cuando pasó a depender del gobierno nacional. 
por su madre, Catalina, que contaba entonces con 21 años, era "sirvienta", ${ }^{19}$ y tenía otra hija apenas mayor. Cuando Catalina solicitó la internación de Micaela en dicha institución, sostuvo que había dejado a su marido por sus malos tratos y que, estando sola, no podía hacerse cargo de la niña. ${ }^{20}$ Micaela permanecería allí hasta 1954, cuando fue devuelta a su madre. Constan registros de que Catalina la visitaba periódicamente. ${ }^{21}$ Cuando volvió a la casa familiar, sus padres estaban juntos y su hermana mayor ya tenía siete años. Al poco tiempo, nacería su hermano menor.

Algunos años más tarde, en agosto de 1963, Micaela fue acogida por la Obra de Protección de la Joven, llevada allí por las hermanas de Santa Ana que la encontraron en la calle mendigando, luego de haberse escapado de su hogar. ${ }^{22}$ La Obra se comprometió a encontrar un trabajo para Micaela, que

${ }_{19}$ Este es el término utilizado en el legajo. Las comillas en este apartado indican que las citas fueron tomadas del legajo abierto por la Sociedad de Beneficencia de la Capital.

${ }^{20}$ Como han mostrado distintos estudios, quienes internaban a un niño(a) en una de las instituciones de beneficencia muchas veces esperaban poder reclamar a esos niños y niñas cuando estuvieran en mejores condiciones económicas (Dalla-Corte Caballero, 2013). Esas pretensiones, sin embargo, no siempre eran factibles. La internación podía suponer la pérdida de la patria potestad, aunque esto sería menos frecuente a partir de los años cuarenta (Villalta, 2012). Incluso si los progenitores conservaban el derecho a solicitar la devolución del o la niña internada, las autoridades institucionales podían colocarlos con distintas familias sin la autorización paterna.

${ }^{21}$ Desde la intervención de la Sociedad de Beneficencia, en 1946, se produjeron cambios importantes como las visitas de los progenitores de los niños y las niñas internadas en las instituciones de ella dependían. Los cambios introducidos por el peronismo en las políticas hacia la infancia habilitaron, en este sentido, una mayor presencia de los familiares de las niñas y los niños internados en estos legajos, a través del registro de sus visitas, de las cartas y de las visitas periódicas que se les realizaban para establecer si estaban o no en condiciones de sostener una eventual reunificación familiar. Algunos de los legajos disponibles, como el que aquí se trabaja, llegan hasta fines de los años sesenta, puesto que, como se dijo arriba, siguen a las niñas y los niños y los jóvenes hasta su salida del sistema, que en algunos casos sólo era con su mayoría de edad. En este sentido, son legajos atravesados por importantes cambios institucionales, como la creación de la Dirección Nacional de Asistencia Pública durante el gobierno peronista, y del Consejo Nacional del Menor, durante el desarrollismo. Esas transformaciones fueron en detrimento del sistema de colocación laboral de menores y, de la mano de la sanción de una ley de adopción en 1948, se favorecieron las colocaciones y guardas con fines de adopción. Sin embargo, las colocaciones laborales mediadas por las instituciones estatales de minoridad siguieron siendo frecuentes para las jóvenes de más de catorce años.

${ }^{22}$ La Asociación Católica Internacional de Protección de la Joven (AcIPJ) fue creada en 1897 en Suiza. Fue parte de las iniciativas católicas que se originaron con el fin de proteger a las mujeres jóvenes que migraban a grandes ciudades en las que no tenían familia. La ACIPJ tuvo una rápida expansión internacional. Después de la segunda guerra mundial, se extendió a América Latina. En Argentina, la Obra de Protección de la Joven (opj) estaba, en efecto, 
quería colocarse en casas de familia, y fueron representantes de dicha institución quienes la internaron en el Colegio María Inmaculada. Su madre, al ser informada del paradero de la joven, pidió que la mantuvieran allí puesto que su situación económica le impedía hacerse cargo de ella. A partir de entonces, comenzó una trayectoria de entradas y salidas de distintas colocaciones domésticas en las que nunca estaría más de unos meses, todas en la ciudad de Buenos Aires. ${ }^{23}$

La primera, en abril de 1964, fue en casa de Juana Marqués, una viuda de 62 años. Su hija, Paula de Galimendi, fue quien solicitó la guarda de Micaela para que le hiciera compañía y, de hecho, dormía en la habitación de servicio de su casa, que estaba en el mismo piso en el que se encontraba el departamento de Juana. De acuerdo con el informe del Departamento de Asistencia Social de agosto de ese año, Micaela estaba muy a gusto en esa casa. Sus tareas consistían en limpiar, puesto que Juana era quien cocinaba y contrataba además a una planchadora. Tenía un sueldo estipulado en 1200 pesos mensuales. De ese monto, 200 pesos eran depositados en el colegio para el ahorro de Micaela y el resto "lo gasta[ba] en ropa y otras cosas necesarias ya que no t[enía] nada". ${ }^{24}$ Micaela cobraba también aguinaldo. ${ }^{25}$ No salía de la casa, salvo los domingos que iba a misa y luego se quedaba a la función de cine del colegio. De acuerdo con el informe, allí se le daba "verdadero trato familiar", la guardadora "la trata[ba] como una hija, la hac[ía] sentir cómoda

afiliada a la AcıPJ y tenía como prioridad la acogida y alojamiento de jóvenes en situación de precariedad. En la actualidad, la OPJ tiene 17 sedes en la Argentina.

${ }^{23}$ Al recibir a Micaela, la opj se puso en contacto con el Consejo Nacional de Protección del Menor. El Consejo resolvió dejar a la joven al cuidado de la opJ, quien fue la responsable de colocarla con la primera familia con la que estuvo. El Consejo, sin embargo, ejerció su papel tutelar a partir de informes periódicos realizados por asistentes sociales que fueron conservados en el legajo inicialmente abierto por la Sociedad de Beneficencia. Las colocaciones laborales se realizaban a partir de los catorce años, edad mínima establecida por el Decreto Ley 326 de 1956 para que el trabajo de menores fuera legalmente admitido. Cada colocación estaba precedida por la elaboración de un informe por parte de las asistentes sociales del Consejo. Se firmaba un contrato en el que se establecían las obligaciones de los guardadores/empleadores, los montos mensuales a abonar, etc. En el legajo no consta el contrato mediado por la oPJ. A ese primer informe, seguían otros en los que las asistentes sociales del consejo daban cuenta de la situación en la que la joven colocada se encontraba.

${ }^{24}$ Leg. 59.991, f. 67. Fondo Secretaría de Niñez, Infancia y Familia. Archivo Intermedio. AGN, Argentina.

${ }^{25}$ Leg. 59.991, f. 71. Fondo Secretaría de Niñez, Infancia y Familia. Archivo Intermedio. AGN, Argentina. 
y segura, la cuida[ba] y vigila[ba] debidamente". ${ }^{26}$ Sin embargo, unos meses más tarde, en marzo de 1965, Micaela sería reintegrada al Consejo Nacional de Menores. ${ }^{27}$ La guardadora sostuvo que Micaela "no aprend[ía] lo que se le enseña[ba], e[ra] sucia, desprolija, altiva y tan mentirosa que tem[ían] que [fuera] una verdadera enfermedad la que padec[ía]". ${ }^{28}$ Micaela declaró que quería volver a colocarse en una casa de familia y no tuvo que esperar mucho para que ello ocurriese. El mismo día en que fue reintegrada al Consejo, fue colocada en otra casa, donde estaría hasta fines de junio de 1965. Allí, nuevamente, fue colocada con una nueva guardadora, con quien estuvo hasta mayo de 1966. Micaela se marchó diciendo que volvía con su madre. Dos semanas después, volvió al Consejo, sola, para solicitar una nueva colocación.

Micaela fue colocada y reintegrada otras cinco veces durante los meses siguientes. La última de esas colocaciones terminó en enero de 1967, cuando pidió volver a casa de los Galimendi, donde estuvo hasta abril del mismo año. Cuando la reintegraron, sostuvieron que así lo había pedido Micaela, pero que ignoraban por qué. La sucesión de colocaciones no culminaría allí. Micaela pidió volver con otra de sus antiguas guardadoras, Berta López, con quien había estado entre agosto y noviembre de 1966, y en cuya casa se quedó hasta mayo de 1967. Luego se fugó, retornando al Consejo cinco meses después, embarazada de tres meses. Durante su embarazo y los primeros meses de vida de su hija estuvo internada en el Amparo Maternal, dependiente de la Asociación de Damas Católicas de San José, en la ciudad de Buenos Aires. De allí salió en nuevas y sucesivas colocaciones, todas mediadas por la Bolsa

${ }^{26}$ Estas son palabras de la asistente social que realiza el informe. Leg. 59.991, f. 70. Fondo Secretaría de Niñez, Infancia y Familia. Archivo Intermedio. AGN, Argentina.

${ }^{27}$ Micaela fue reintegrada por su primera "empleadora" al Consejo, y entonces su caso fue derivado a la División Bolsa de Trabajo dependiente del mismo organismo. Más tarde, fue el Departamento de Ubicación el que intermedió en las nuevas colocaciones que tendría Micaela. El contrato, que en este caso consta en el legajo, establecía que la guardadora "proveerá de los medios necesarios para su educación, prodigará trato familiar y dispensará los cuidados que la salud de la misma exija con conocimiento de este Organismo. Asignará a la menor por su colaboración por las tareas del hogar una remuneración mensual de $\$ 2000 \mathrm{~m} / \mathrm{n}$. debiendo depositar en su cuenta de ahorro la suma de $\$ 150 \mathrm{~m} / \mathrm{n}$., y el resto entregarlo a la menor para sus gastos personales." Leg. 59.991, f. 73. Fondo Secretaría de Niñez, Infancia y Familia. Archivo Intermedio. AGN, Argentina. La fórmula usada en este contrato fue retomada en los siguientes contratos de colocación mediados por el Consejo.

${ }^{28}$ Palabras de la guardadora al momento de reingresar a Micaela al sistema, registradas por la asistente social. Leg. 59.991, f. 70. Fondo Secretaría de Niñez, Infancia y Familia. Archivo Intermedio. AGN, Argentina. 
de Trabajo del Consejo Nacional de Menores, en las que estuvo con su hija. Finalmente, en enero de 1970 se pierde su rastro; tras haber alcanzado la mayoría de edad a los 21 años, se cierra su expediente.

La historia de Micaela replica en muchos sentidos las de otras niñas y jóvenes que transitaron las instituciones de minoridad en estos años. La sucesión de colocaciones domésticas, fugas y devoluciones era corriente, aunque quizá no en el número que alcanzaron en este caso. ${ }^{29}$ Las quejas de las guardadoras también son similares a las que se encuentran en otros legajos donde las niñas eran caracterizadas como rebeldes, desobedientes, sucias, o indolentes. ${ }^{30}$ La de Micaela llama la atención no sólo por la cantidad de colocaciones que tuvo, sin dudas asociada a su larga trayectoria en las instituciones de minoridad, sino también por sus pedidos reiterados de ser colocada en casas de familia y de volver con dos de sus antiguas guardadoras. La mayor parte de las veces en que fue reintegrada al Consejo, sostuvo que había sido ella quien lo había solicitado, ya fuera porque se sentía muy sola, porque no "la sacaban" lo suficiente, porque no se llevaba bien con la persona que oficiaba de guardadora, entre otros motivos. Entre los quince y 21 años, en dos ocasiones escapó a la tutela estatal: la primera al volver con su madre y la segunda al irse con el padre de su hija. En todas las oportunidades, Micaela solicitó una nueva colocación. Posiblemente no tuviera muchas alternativas $y$, en todo caso, seguramente no eran mejores.

Pese a haber sido institucionalizada a los seis meses de edad, Micaela había vuelto con su madre a los seis años, sólo para regresar bajo la órbita del Consejo a los quince años. Para entonces, en Micaela se había instalado la sospecha de que quien decía ser su madre en realidad no lo era, tal como lo manifestara en una de las evaluaciones psicológicas que se le realizaran. Dicha sospecha, recuperada también en la voz de las vecinas de su madre entrevistadas por una visitadora social (que no sólo la creían verosímil, sino cierta), se fundaba en que la había "abandonado" en la Casa Cuna, en la diferencia en el trato que recibía en relación con sus hermanos, y en los malos tratos que le prodigaba. ${ }^{31}$ Micaela tenía una relación tensa con su madre. Las

${ }^{29}$ Sobre las colocaciones laborales realizadas por las instituciones de minoridad a principios de siglo, consúltese Aversa (2014). Sobre las fugas de las niñas de ese sistema en los años treinta y cuarenta, véase Leo (2017).

30 En un sentido similar, véase Gentili (2018).

${ }^{31}$ Leg. 59.991, fs. 65 y 66. Fondo Secretaría de Niñez, Infancia y Familia. Archivo Intermedio. AGN, Argentina. 
visitas que le hacía los domingos al Colegio María Inmaculada, en sus días de descanso, solían terminar en "escándalos", lo que hizo que eventualmente fueran prohibidas por las autoridades del colegio. De acuerdo con sus guardadoras, Micaela volvía "trastornada y nerviosa". ${ }^{32}$

En este escenario, la perspectiva de volver con su familia de origen no parece haber sido muy alentadora, y al menos durante un tiempo, tampoco era realmente una opción, puesto que no conocía su nuevo domicilio. Buscar otro tipo de empleo quizá hubiera sido posible, aunque siendo menor, casi sin instrucción formal y, luego, teniendo una hija pequeña, seguramente no era algo sencillo. Aun así resulta llamativo que quisiera volver con dos de las guardadoras con las que había estado, en especial siendo este pedido previo a su embarazo. También es significativo que, pese a las quejas que manifestaron cuando la habían reintegrado al Consejo, ellas también la aceptaran nuevamente en sus hogares. Más allá del trabajo que Micaela realizaba, y del salario y la vivienda que le daban a cambio, ¿cómo puede caracterizarse la relación que las unía?

En el informe de una asistente social realizado en casa de los Galimendi, en enero de 1967, Micaela "evidencia[ba] querer a su empleadora". Del mismo modo, señalaba que la "empleadora [era] tranquila, [tenía] carácter [y] ascendiente moral sobre la menor" y, en su opinión, sentía afecto por ella. ${ }^{33}$ La asistente también observaba que Micaela tenía un "estado de nerviosidad muy notorio, inestabilidad emocional [y] problemas de celos con motivos de llamadas telefónicas a la empleadora de una menor que trabajó anteriormente". ${ }^{34}$ En el mismo informe, dejaba constancia de que Micaela pedía al consejo que averiguara el paradero de su madre porque la extrañaba. Es posible que estos sentimientos fueran los que la impulsaran a marcharse, solicitando volver a casa de Berta López, donde estaría unos meses. Del final de esa relación sabemos aún menos, puesto que no contamos con un informe similar al citado arriba, y al momento de informar su fuga, la guardadora no aportó mayores datos sobre sus posibles motivos.

${ }^{32}$ Leg. 59.991, fs. 65 y 66. Fondo Secretaría de Niñez, Infancia y Familia. Archivo Intermedio. AGN, Argentina.

${ }_{33}$ Leg. 59.991, f. 103. Fondo Secretaría de Niñez, Infancia y Familia. Archivo Intermedio. AGN, Argentina.

34 Leg. 59.991, f. 103. Fondo Secretaría de Niñez, Infancia y Familia. Archivo Intermedio. AGN, Argentina. 
Independientemente de que el "verdadero trato familiar" con que las asistentes sociales describían la relación entre guardadores/empleadores y las menores fuera sólo una fórmula protocolar, el retorno de Micaela con dos de sus antiguas guardadoras permite pensar que al menos en algunos casos esas relaciones daban lugar a la expectativa de afecto y protección. Años después de haber estado a su servicio, y a pesar de que en su momento la hubieran reintegrado al Consejo no por faltas en su trabajo sino en su "carácter" ${ }^{35}$ (la calificaban de sucia, desprolija, altiva y mentirosa), Micaela podía esperar que volvieran a tomarla. Lo que es más, el informe de la asistente social al que hacemos referencia sugiere que Micaela esperaba ocupar un lugar preciso en casa de los Galimendi (y presumiblemente también en la de los López), un lugar que podía ser puesto en riesgo por las ocasionales apariciones de otra joven que lo había ocupado. El andamiaje de jerarquías que organizaba la vida doméstica de los Galimendi preveía un lugar (subordinado) para ella, que suponía el intercambio de trabajo y dinero, pero también de afecto y protección.

Micaela había rechazado el lugar -también subordinado- que se le asignara en su familia de origen y el deber que él suponía: aportar dinero al hogar. Recordemos que su madre sólo la reclamó a las instituciones de minoridad a los seis años y que, al escapar de su casa a los quince, sostuvo que sus padres la obligaban a mendigar. Del dinero que cobró en sus sucesivas colocaciones, Micaela no enviaba una suma regular a su madre, como sí lo hacía Ofelia, cuyo caso fue analizado en el apartado anterior. El amor como obligación de contribuir al presupuesto familiar parece haber sido clave en la pertenencia a la familia de origen, al igual que ocurría en el caso de Ofelia, sólo que Micaela no cumplió con él.

La decisión de volver con sus antiguas guardadoras puede haber estado anclada en la expectativa de afecto, pero ese afecto estaba condicionado a su obediencia y deferencia, es decir, a la observación de las jerarquías que la ubicaban en un lugar de intensa subordinación. En última instancia, Micaela terminó también rechazando ese lugar. Cuando los Galimendi la reintegraron al Consejo por primera vez, de hecho, indicaban como causa su altivez y su incapacidad para adecuarse a los parámetros de comportamiento establecidos. Se insistía en que no aprendía lo que se le enseñaba, pero esto difícilmente pudiera referirse a las tareas domésticas en sí, puesto que al mismo tiempo

${ }^{35}$ Leg. 59.991, f. 113. Fondo Secretaría de Niñez, Infancia y Familia. Archivo Intermedio. AGN, Argentina. 
sostenían que Micaela era muy buena para ellas, lo que se repitió en todas las colocaciones que tuvo. Del mismo modo, el nerviosismo y la inestabilidad señalados en distintos informes de las visitadoras y asistentes sociales dan cuenta de una imposibilidad de adecuarse a los parámetros emocionales que dominaban en las casas en las que fue colocada: podía haber afecto, pero no en la forma que se esperaba en esas relaciones.

La diferencia con el caso de Ofelia es notoria. Ofelia era obediente y no sólo aceptó el lugar subordinado que le era otorgado en casa de los Ortega, sino que lo hizo con gratitud y, gracias a ello, fue incorporada, aunque en una posición periférica y subalterno, a sus redes de protección. En cambio, la integración de Micaela a las familias de sus guardadores fue, hasta donde sabemos, limitada y pasajera. Si la relación de Ofelia con las familias de sus guardadores/empleadores era más bien porosa, las que encontró Micaela fueron más duras, difícilmente transitables y, en última instancia, expulsivas.

\section{FRANCISCA}

Francisca nació en 1939 en una zona rural del Partido de Castelli, provincia de Buenos Aires. Su padre trabajaba en la empresa La California, que producía dulces y sidras. Vivió allí hasta que sus padres se separaron. Su madre, entonces, se trasladó al Gran Buenos Aires y desde allí colocó, sin intervención institucional, a cinco de sus ocho hijos en distintas casas de familia en Dolores, de donde era originalmente. Francisca fue colocada en casa de María y Antonio Fernández, un matrimonio con tres hijos, dos de los cuales estaban casados. No es claro qué edad tenía Francisca para entonces; en las versiones de los distintos entrevistados tenía entre seis y nueve años, es decir que cuando fue colocada era bastante más pequeña que las niñas cuyas historias se presentaron en los apartados previos. En esa casa, Francisca nunca tuvo tareas asignadas pero colaboraba con todo aquello que se necesitaba, especialmente labores domésticas.

A partir de entonces, y de acuerdo con todas las voces entrevistadas, comenzó a formar parte de la familia de los Fernández. Aunque desde una mirada normativa podría verse esta relación como una de empleo doméstico, que contravenía las regulaciones vigentes en varios puntos, no es esta la mirada de las y los actores. Como recuerda una de las nietas de María, "Francisca 
entró y [...] conquistó, ella ocupaba mucho espacio afectivo" ${ }^{36}$ Francisca vivió con María y Antonio hasta que ambos murieron. Luego, se mudó con Chela, una de las hijas de los Fernández, y su marido, Roque, y vivió con ellos hasta que también fallecieron. A partir de entonces vivió con María Isabel, hija de Chela y Roque, a quien cuidó también hasta sus últimos días y en cuya casa siguió residiendo luego de su muerte. Allí fue bautizada como Mamina, el apelativo con el que aún hoy la recuerdan los hijos y nietos de María Isabel. Francisca, que nunca se casó ni tuvo hijos propios, murió en 2015.

Ahora bien, el vínculo con su familia de origen, los Bravo, no se cortó completamente. En Dolores y otras localidades de la zona, vivían algunos de sus hermanos con quienes tuvo una relación, no muy estrecha, pero sostenida en el tiempo. Francisca participaba de algunos eventos familiares, como casamientos y cumpleaños, e incluso ayudaba económicamente a algunos de ellos. Tanto su madre como su padre intentaron recomponer la relación con ella, aunque con distinta suerte. Según todos mis informantes, ella nunca perdonó a su madre por haberla "abandonado", y aunque fue a visitarla en numerosas oportunidades, Francisca no quería verla. En cambio, a pesar de que el trato con su padre no parece haber sido muy asiduo, cuando él falleció, fue Francisca quien se encargó de trasladar sus restos del cementerio de Castelli al Panteón del Círculo Católico de Obreros de Dolores.

En la mirada de los Fernández, ellos se habían convertido en su familia. El papel secundario que ellos asignaron a los Bravo, no siempre fue aceptado sin resistencias. Por ejemplo, una de sus sobrinas sostuvo:

cuando ella fallece, en el aviso no pusieron a los hermanos. Pusieron a la familia de ellos. Entonces yo qué hice: fui al diario y puse un [aviso]: "siempre te voy a llevar en mi corazón, tu sobrina María Isabel Tomasini Bravo" y otra con todos los hermanos. O sea, ella tenía trato con los hermanos, no es que ella no sabía o no se trataba. Yo vi mal el no haber puesto a los hermanos. Porque ellos la pusieron como que no tenía madre, no tenía padre, no tenía hermanos, y a mí eso me dolió. ${ }^{37}$

${ }^{36}$ En este apartado, las comillas indican citas de las entrevistas. Entrevista a María Angélica realizada el 2 de diciembre de 2017, en Dolores, Provincia de Buenos Aires, Argentina.

${ }^{37}$ Entrevista realizada a María Isabel el 22 de diciembre de 2017, en Dolores, Provincia de Buenos Aires, Argentina. 
El lugar de Francisca en la familia de los Fernández varió a lo largo del tiempo. Llegó como niña colocada para su crianza, pero ella sería quien terminaría criando varias generaciones de niños(as) en esa familia. Su madre la colocó allí porque no podía cuidar de ella, pero fue Francisca la que tuvo a su cuidado tanto a María, como a Chela (hija de María), Roque (yerno de María), y, finalmente, a María Isabel (nieta de María). Francisca era muy religiosa, y muchas de las personas entrevistadas sostuvieron que sus creencias habían sido la fuente de su soltería: "Ella era muy entregada a Dios, muy devota, y yo creo que el motivo de ella de no casarse fue ese, ella estaba casada con Dios." ${ }^{138}$ Sin embargo, algunos entrevistados también señalaron la demanda de cuidado de los distintos miembros de la familia Fernández como obstáculo para que ella formara una familia propia: "ella cuidaba mucho a Chela y a don Roque, era muy compañera de ellos", 39 "ella crió a los hijos de María Isabel". ${ }^{40}$

La muerte de personas clave en la familia Fernández permite ver el cambio en el lugar asignado a Francisca. Cuando María murió, en los avisos fúnebres Francisca aparecía como una "hija en el afecto". Cuando murió Roque, su nombre aparecía junto a "hermana en el afecto". En ambos casos, los espacios generacionales se mantuvieron: Roque era el yerno de María. Ahora bien, cuando murió Chela, Francisca aparecía nuevamente como "hija en el afecto", es decir que había cambiado de generación. Y, años después, sería identificada como "hermana en el afecto" de la hija de Chela, María Isabel. Ese lugar se confirma entre los más jóvenes: Sergio, uno de los hijos de María Isabel, sostenía: "ella fue mi tía, yo le puse un apodo, que era 'Mamina', porque me salió, y así se la conoce en nuestra familia, y fue la que nos crió, tanto a mí como a mis hermanos, estuvo permanentemente en la crianza nuestra, fue nuestra tía, y nuestra segunda mamá siempre". ${ }^{41}$

La fórmula "en el afecto" permitía incluirla en el entramado familiar, pero suponía también un límite a esa inclusión. Más adelante, en la misma entrevista, Sergio diría:

38 Entrevista realizada a María Isabel el 22 de diciembre de 2017, en Dolores, Provincia de Buenos Aires, Argentina.

39 Entrevista realizada a María Isabel el 22 de diciembre de 2017, en Dolores, Provincia de Buenos Aires, Argentina.

${ }^{40}$ Entrevista realizada a Mercedes el 2 de diciembre de 2017, en Dolores, Provincia de Buenos Aires, Argentina.

${ }^{41}$ Entrevista realizada a Sergio el 17 de diciembre de 2016, en Dolores, Provincia de Buenos Aires, Argentina. 
nunca fue considerada una empleada. Siempre fue mi tía, y la hermana de mi mamá. De hecho, muchas veces con la gente externa uno le tenía que explicar que era mi tía pero mi tía de cariño, de crianza. No mi tía de sangre, porque ella era de apellido Bravo, su papá es de origen portugués, y mi mamá es Aguilar. Es decir, no había una relación... Mi abuela era Fernández, la familia de la que ella venía era Franco, o sea que no había una cuestión de apellido, pero sí de relación. Siempre fue la hija pequeña de mi bisabuela, o la hija de mi abuela, y la hermana de mi mamá. [...] nunca se habló de una situación de empleo, siempre fue una situación de crianza. ${ }^{42}$

Sergio ofreció esta respuesta ante la pregunta por el arreglo económico que tenían con Francisca. La pregunta estaba orientada a indagar si ella cobraba un sueldo, puesto que hasta los años setenta no trabajó fuera de la casa de los Fernández. Francisca hizo el bachillerato siendo adulta, y luego estudió magisterio, aunque no ejerció. Trabajó en distintas dependencias municipales, en un hogar de niños, y luego de recibirse como bibliotecaria, quedó a cargo de dos bibliotecas. Pero todo esto fue a partir de sus 30 años. Para el periodo anterior, tanto Sergio como las otras personas que entrevisté sostuvieron que nunca le faltó nada y que es probable que recibiera algo de dinero para sus gastos personales, pero no como salario, sino como la asignación que podía haber tenido una hija en las mismas condiciones.

Dinero, trabajo y afecto se cruzan en la caracterización de la relación que unía a Francisca con los Fernández. No cobraba un salario porque era de la familia y, como tal, recibía lo "necesario". También como parte de la familia heredó un auto, el Gordini, que había sido de Roque y ella luego cambió por un Fiat 147, y aún más tarde por un Ford K. Ahora bien, los bienes que ella tenía o los que usufructuara en vida, como la casa de María Isabel, quedaron a su muerte en manos de los Fernández. Ni siquiera aquellos de menor valor fueron heredados por su familia de origen. En términos patrimoniales, Francisca pareciera haberse integrado a la familia de los Fernández, cortando los vínculos con la suya de origen. Integrada, sin embargo, no quiere decir de manera igualitaria: el auto no se equipara con la herencia recibida por María Isabel, ni antes por los hijos de María. Tampoco las condiciones de esa integración eran las mismas; hicieran lo que hicieran, los hijos, nietos y bisnietos

${ }^{42}$ Entrevista realizada a Sergio el 17 de diciembre de 2016, en Dolores, Provincia de Buenos Aires, Argentina. 
de María recibirían lo legalmente establecido; Francisca sólo heredaría en tanto hubiera voluntad de causantes y deudos. Su estatus no era el de hija, era inferior y era condicional.

Francisca fue muy querida por todos los Fernández. La recuerdan con cariño y gratitud por estar siempre, como aparece en la voz de Sergio en el siguiente fragmento, "al pie del cañón":

Francisca siempre con mucha vocación religiosa, un carácter especial, excelente, siempre de servicio, siempre bien educada, siempre con buenos términos, siempre con una sonrisa, muy positiva. [...] Siempre estaba levantada desde temprano, limpiaba la casa, salía. Acompañó mucho a mi abuela, fue su compañera hasta el último día, fue su compañera de vivienda y de asistencia. A mi mamá le costaba mucho. Mi abuela terminó con Alzheimer, no con Alzheimer, con un problema tipo Alzheimer, no perdida totalmente, pero sí con muy poca memoria reciente, por lo cual uno le explicaba algo y se lo tenía que explicar 15 veces. Y mamá no soportaba eso, le dolía mucho, le molestaba mucho, no podía, y se lo cuestionaba, y ella [Francisca] estaba siempre al pie del cañón, inclusive con la gente mayor que empiezan a tener problemas con el dinero, que le falta plata, que le dice..., se bancaba cualquier cosa. ${ }^{43}$

Ya fuera que lo hiciera o no con gusto, es probable que Francisca percibiese que su pertenencia a la familia de los Fernández dependía de la vocación "de servicio" expresada por Sergio en la entrevista. Si bien Sergio usa el término "vocación" para hablar de la devoción religiosa de Francisca, ese término se imbrica con el servicio del que habla después. Del fragmento citado y de las otras entrevistas realizadas, se desprende que no sólo importaba el cuidado que ella brindaba, sino el hecho de que lo hiciera con alegría, "con una sonrisa", que aceptara siempre y de buen talante lo que se esperaba de ella, lo que nadie más estaba dispuesto a hacer. Si, como mencionábamos arriba, el servicio doméstico está caracterizado por la expectativa de deferencia por parte de los empleadores, aquí encontramos un deslizamiento: la condición de pertenencia a la familia implica que la deferencia debe ser voluntaria; el

${ }^{43}$ Entrevista realizada a Sergio el 17 de diciembre de 2016, en Dolores, Provincia de Buenos Aires, Argentina. 
servicio, una vocación; la obediencia, alegre. ${ }^{44}$ Estas expectativas están fuertemente marcadas por los estereotipos de género que caracterizan la feminidad heterosexual hegemónica, asociados a la madre amorosa y abnegada.

A diferencia de lo que observábamos en los casos anteriores, Francisca pareciera haber sorteado la frontera que marcaba el ingreso a la familia de sus guardadores de una forma más permanente y accediendo a un lugar de relevancia, al menos en términos afectivos, aunque no por ello igualitarios. Al contrario de lo ocurrido con Ofelia, el centro de su sistema familiar estaba con los Fernández y el vínculo que mantenía con sus parientes de origen era, en cambio, más distante. El precio de ese tránsito parece haber sido una demanda de cuidado tan intensa que supuso, entre otras cosas, la renuncia a tener una familia propia. El cuidado debía ser realizado con afecto, pero sobre todo con alegría, con verdadera vocación de servicio.

\section{FRONTERAS Y JERARQUÍAS FAMILIARES}

¿Qué hace que un vínculo sea caracterizado como familiar? Hace ya casi dos décadas, Eric Fassin (2005) insistía en la imposibilidad y, sobre todo, la inconveniencia de dar una única definición de familia. Según dicho autor, reducía la diversidad de arreglos y nociones que hacen a los usos sociales del concepto. En este sentido, señalaba que las definiciones más provechosas en materia de producción de conocimiento eran no las que se hacían con anterioridad al análisis empírico, sino aquellas a las que se arribaba con posterioridad a él. ¿Qué nociones de familia podemos observar en las tres historias analizadas?

La mercantilización y laboralización de los vínculos en los que se intercambian trabajo doméstico y cuidados no impide que muchas empleadas domésticas sigan hoy siendo consideradas "como de la familia". En el caso de las niñas colocadas para el servicio doméstico, el carácter de las relaciones es aún más ambiguo y liminal. Por un lado, el trabajo no siempre era remunerado $y$, aun cuando lo era, lo que permitía marcar el carácter o el grado familiar de un vínculo no era la presencia o ausencia de dinero, sino la forma en que circulaba y los sentidos que se le asignaban. Por otro lado, la presencia de

${ }^{44}$ Esta disposición recuerda la obediencia alegre de la que hablaba Stearns (2014) para dar cuenta de algunos de los cambios sustanciales en relación con la infancia ocurridos en el tránsito a la modernidad. 
afecto no suponía un trato igualitario, sino que se lo asociaba a la protección y a la obediencia.

La respuesta de Sergio ante la pregunta por el arreglo económico que su bisabuela y luego su abuela tenían con Francisca es significativa. Aclarar que ella no cobraba un salario era clave para mostrar que ella formaba parte de su familia. Al contrario, en la vida de Ofelia, el momento en que comenzó a cobrar un salario marcó el inicio de una trayectoria de mercantilización que culminaría con nuevos y sucesivos empleos en el servicio doméstico. En el caso de Micaela, el depósito mensual de un monto de dinero en una caja de ahorros, así como el pago puntual de salarios y aguinaldos, era también muestra de un límite del carácter familiar de la relación, marcado por su laboralización. El uso de la palabra salario o aguinaldo en los documentos conservados en su legajo es significativo. También lo es el control estatal de esa relación.

Esto no significa que el dinero no fuese intercambiado en el marco de relaciones caracterizadas como familiares. Cobrar un salario, por ejemplo, permitió reforzar el vínculo de Ofelia con su familia de origen. El dinero que enviaba periódicamente a su madre puede ser leído como parte de un deber sostenido en el afecto. En el caso de Francisca, las pequeñas sumas de dinero que se le asignaban para sus gastos, y el legado que recibió marcaban su condición de parte de la familia Fernández. La forma que adoptaba el intercambio monetario suponía que su origen estaba en un vínculo familiar y no en una relación laboral mercantilizada: el auto que le dejara Roque era menos un pago por los servicios prestados que una muestra de afecto. La forma en que el dinero circulaba también resultaba importante para delimitar quiénes formaban parte de la familia Fernández. Francisca podía recibir regalos, legados, y usufructuar de por vida distintos bienes, pero esos beneficios no eran transmisibles a su familia de origen. Y, finalmente, el valor de los bienes asignados a cada quien era una muestra clara del estatus correspondiente en las jerarquías familiares.

Como muestran las historias analizadas, la caracterización de un vínculo como familiar suponía formas específicas de desigualdad. Quienes se ubicaban en una posición no sólo subordinada sino también periférica podían tener la expectativa de protección, pero a cambio se les requería no sólo obediencia, sino también deferencia. El caso de Micaela es, en este sentido, revelador. Habiendo pasado sólo unos meses con sus guardadores y habiendo terminado la relación en términos más o menos difíciles, pudo volver a 
su casa cuando lo requirió. Del mismo modo, Ofelia pudo solicitar la ayuda de guardadores y empleadores cuando su familia de origen lo necesitó. Ahora bien, para activar esas redes, ambas debieron adecuarse a los modelos de comportamiento y estándares emocionales de los guardadores, lo que hicieron con diferente suerte: si Ofelia pudo contar con esas redes tiempo después de que hubiera terminado la relación con sus empleadores, Micaela fue expulsada de ellas por su imposibilidad de adecuarse dichos estándares.

Francisca, por su parte, no sólo mostró afecto hacia los Fernández, sino que rápidamente se adaptó a las pautas establecidas, y se movió dentro de ellas el resto de su vida. Realizó trabajo doméstico, cuidó a niños y ancianos, y aceptó las tareas que nadie más podía o quería hacer, y al hacerlo mostró alegría y vocación de servir. Atravesar esa frontera familiar (y emocional) supuso para ella aceptar el lugar subordinado que se le asignaba: la correcta expresión del afecto suponía una alegre deferencia.

Aunque limitadas al espacio geográfico comprendido por la ciudad y la provincia de Buenos Aires, las tres trayectorias de vida reconstruidas en este artículo permiten reflexionar sobre la complejidad de las nociones de familia que subyacían en las prácticas de crianza y colocación desarrolladas en la Argentina en las décadas centrales del siglo xx. Sustancialmente menos numerosas que antaño, aún eran instancias de construcción de sentido sobre las jerarquías, el afecto, y las protecciones articuladas en el mundo doméstico, en torno a vínculos de parentesco que trascendían la sangre y la alianza.

El análisis de estas historias también permite reflexionar sobre el lugar del afecto en la construcción de las desigualdades sociales. La caracterización de un vínculo como familiar y la presencia de afecto no sólo no suponían relaciones igualitarias, sino que eran elementos centrales en la estructuración de las jerarquías que ordenan el mundo doméstico. Considerar las relaciones en las que se intercambiaba trabajo doméstico y cuidados por dinero sólo a partir de la categoría de empleo o de las asimetrías propias del mercado, obtura la comprensión de su complejidad, y de lo que ha obstaculizado el pleno reconocimiento de las trabajadoras como tales.

¿En qué medida las nociones de familia analizadas en este texto informan aún hoy el imaginario en torno de las relaciones en las que se intercambia ese tipo de trabajo?, ¿cómo influyen dichas representaciones en las expectativas respecto de los deberes de quienes participan de ellas, y en la definición de lo que es justo?, ¿en qué punto la persistencia de estas nociones ha limitado y todavía limita el reconocimiento y ejercicio de los derechos la- 
borales de quienes realizan trabajo doméstico y de cuidados a cambio de dinero? Aunque este texto no busca responder estos interrogantes, quizá pueda contribuir a plantearlos.

\section{LISTA DE REFERENCIAS}

Allemandi, C. (2017). Sirvientes, criados y nodrizas. Una historia del servicio doméstico en la ciudad de Buenos Aires (fines del siglo xIx y principios del xx). Buenos Aires: Teseo. Anderson, M. (1988). Aproximaciones a la historia de la familia occidental (1500-1914). Madrid: Siglo XXI.

Arfuch, L. (2002). El espacio biográfico. Dilemas de la subjetividad contemporánea. Buenos Aires: Fondo de Cultura Económica.

Aversa, M. M. (2014). Un mundo de gente menuda. El trabajo infantil tutelado. Ciudad de Buenos Aires, 1870-1920 (Tesis de doctorado inédita). Universidad de Buenos Aires, Argentina.

Blum, A. (2011). Speaking of work and family: reciprocity, child labor, and social reproduction, Mexico city, 1920-1940. Hispanic American Historical Review, 91(1), 63-95.

Borges, M. (2016). For the good of the family: migratory strategies and affective language in Portuguese migrant letters, 1870s-1920s. The History of the Family, 21(3), 368-397. DoI: https://doi.org/10.1080/1081602X.2016.1208620

Bourdieu, P. (1994). L'esprit de famille. En Raisons pratiques sur la théorie de l'action. París: Editions du Seuil.

Cosse, I. (2010). Pareja, sexualidad y familia en los años sesenta. Una revolución discreta en Buenos Aires. Buenos Aires: Siglo XXI.

Dalla-Corte Caballero, G. (2013). El Archivo de Señales del Hogar del Huérfano de Rosario. Niñez, identidad y migración (1879-1914). Rosario: Prohistoria.

Deveali, M. (1956). Comentario. Régimen de previsión para el personal del servicio doméstico. Revista Derecho del Trabajo, 434-439.

Fassin, E. (2005). Usos de la ciencia y ciencia de los usos. A propósito de las familias homoparentales. Debate Feminista, 32, 52-73.

Fraser, N. (1997). Iusticia Interrupta. Reflexiones críticas desde la posición "postsocialista". Bogotá: Siglo del Hombre/Universidad de Los Andes.

Gentili, A. (2018). Veladuras. El servicio doméstico de niñas y jóvenes en la narrativa judicial de los años sesenta en Córdoba, Argentina. Secuencia. Revista de Historia y 
Ciencias Sociales, Edición especial, 85-118. DoI: https://doi.org/10.18234/secuencia. v0i0.1659

Goldstein, D. (2003). Laughter out of place: race, class, violence, and sexuality in a Rio Shantytown. Berkeley: University of California Press.

Gorbán, D. y Tizziani, A. (2014). Inferiorization and deference: The construction of social hierarchies in the context of paid domestic labor. Women's Studies International Forum, 46, 54-62. DoI: https://doi.org/10.1016/j.wsif.2014.01.001

Hareven, T. (1995). Historia de la familia y la complejidad del cambio social. Boletín de la Asociación de Demografía Histórica, XIII(1).

Leo, M. (2015). Sobre “depósitos" y "rescates": una aproximación cuantitativa a la circulación de niños como práctica y como estrategia familiar de los sectores populares. Buenos Aires: 1930-1945. Ponencia presentada en las IV Jornadas de Estudios sobre la Infancia. Buenos Aires, Argentina.

Leo, M. (2017). De fugas y otros desafíos: la agencia de niños, niñas y adolescentes frente a la disciplina asilar y la colocación. Buenos Aires, 1920-1948. Ponencia presentada en las Jornadas Interescuelas de Departamentos de Historia, Mar del Plata, Argentina.

Lerussi, R. (2014). La retórica de la domesticidad. Política feminista, derecho y empleo en la Argentina. La Plata: Edulp.

Milanich, N. (2009). Children of fate. Childhood, class and the state in Chile, 1850-1930. Durham and London: Duke University Press.

Pérez, I. y Canevaro, S. (2015). Languages of affection and rationality: household workers' strategies before the Tribunal of Domestic Work (Buenos Aires, 19562013). International Labor and Working-Class History, 88, 130-149.

Pérez, I. (2013). Entre las normas y sus usos. Servicio doméstico, trabajo, intimidad y justicia en el Consejo de Trabajo Doméstico (Buenos Aires, 1956-1962). Nuevo Mundo, Mundos Nuevos. DoI: https://doi.org/10.4000/nuevomundo.65167

Pérez, I. (2018). ¿Criadas o trabajadoras? Lenguajes, representaciones y estrategias frente a la justicia laboral (Buenos Aires, 1956-1970). Revista de Historia y Justicia, $11,101-124$.

Portelli, A. (2007). The order has been carried out: history, memory, and meaning of a nazi massacre in Rome. Nueva York: Palgrave Macmillan.

Remedi, F. (2012). "Esta descompostura general de la servidumbre.” Las trabajadoras del servicio doméstico en la modernización argentina, Córdoba, 1869-1906. Secuencia. Revista de Historia y Ciencias Sociales, 84, 41-69.

Rollins, J. (1985). Between women: domestics and their employers. Filadelfia: Temple University Press. 
Rustoyburu, C. (2012). Infancia, maternidad y paternidad en los discursos de la Nueva Pediatría. Buenos Aires, 1940-1976 (Tesis de doctorado inédita). Universidad de Buenos Aires.

Schneider, D. (1980). American Kinship: A cultural account. Chicago y Londres: Chicago University Press.

Segalen, M. (2013). Sociología de la familia. Mar del Plata: Eudem.

Stearns, P. (2014). Obedience and emotion: A challenge in the emotional history of childhood. Journal of Social History, 47(3), 593-611.

Thompson, P. (1988). La voz del pasado. La historia oral. Barcelona: Ediciones Alfons El Magnanin, Institu Valenciana de estudis y Investigació.

Vallagårda, K., Alexander, K. y Olsen, S. (2017). Emotion and the global politics of childhood. En S. Olsen (ed.), Childhood, youth and emotions in modern history. National, colonial and global perspectives (pp. 12-34). Nueva York: Palgrave.

Vázquez Lorda, L. (2010). El otro ángel del hogar es mujer, trabajadora y asalariada. Las empleadas domésticas y el catolicismo en la Argentina de los años 1950. En N. Álvarez (comp.), Familia, género y después... Itinerarios entre lo público, lo privado y lo intimo (pp. 107-126). Rosario: Prohistoria.

Villalta, C. (2012). Entregas y secuestros. El rol del Estado en la apropiación de niños. Buenos Aires: Editores del Puerto/cels.

Zelizer, V. (1994). Pricing the priceless child: the changing social value of children. Princeton: Princeton University Press.

Zelizer, V. (2009). La negociación de la intimidad. Buenos Aires: Fondo de Cultura Económica.

\section{OTRAS FUENTES}

\section{Archivo}

AGN Archivo General de la Nación, Argentina. 